\title{
Effects of Neonatal Massage on Jaundiced Neonates Undergoing Phototherapy
}

\author{
S.A.Dabour ${ }^{1}$, E.H.Assar ${ }^{1}$, Y.M.Ismail ${ }^{1}$, Y.M.Ismail ${ }^{2}$ and M.A.Afify ${ }^{1}$ \\ ${ }^{1}$ Pediatrics Dept., Faculty of Medicine, Benha Univ., Benha, Egypt \\ ${ }^{2}$ Clinical and Chemical Pathology Dept., Faculty of Medicine, Benha Univ., Benha, Egypt
}

Abstract

E-Mail:Mhmdabdeltawab735@gmail.com

More than half of newborns and $80 \%$ of preterm children develop clinical symptoms of jaundice . Massage is regarded as a new care method for neonates with a positive effect on neonatal disease treatment and health care .The present study aimed to assess role of massage therapy for reduction of neonatal jaundice in neonates undergoing phototherapy This examination was a clinical preliminary, which was done on 100 neonates (who were conceded in the neonatal emergency unit Benha University and Benha Childern Hospital).Studied neonates were partitioned into 2 gatherings ( Massage gathering and control bunch ). Absolute serum bilirubin (TSB) level diminished by time in charge and back rub gatherings. No critical contrasts were found in TSB level among back rub and control bunches by the first and second days. While, by the third day, TSB level was fundamentally lower in rub bunch when contrasted with control gathering. Back rub treatment could decrease TSB level and increment the recurrence of poop in solid term neonates getting phototherapy for jaundice.

Keywords: Jaundice, Massage, Neonatal Intensive Care Unit.

\section{Introduction}

Hyperbilirubinemia usually happens during the principal seven day stretch of birth and one of the most well-known reasons for hospitalization among term and preterm neonates [1]. Neonatal hyperbilirubinemia is viewed as when the absolute serum bilirubin (TSB) transcends the 95th percentile for age during the main seven day stretch of life [2].

As indicated by accessible proof, $60 \%$ of term newborn children and $80 \%$ of preterm babies have clinical manifestations including sclera and yellowish skin brought about by an expansion in serum bilirubin levels, separately [3]. The awkwardness among conjugation and bilirubin creation as the primary system of jaundice prompts the expansion in bilirubin levels [4].

Infants are at a higher danger of raised bilirubin because of the fast breakdown of red platelets, slow intestinal developments and youthful liver [5].

Back rub is acknowledged as a non-obtrusive and valuable treatment, not requiring unique gear [6]. what's more, as a sheltered methodology for babies $>31$ weeks [7].

The current examination meant to: evaluate the job of back rub treatment for decrease of neonatal jaundice in neonates experiencing phototherapy in neonatal concentrated consideration units in Benha University Hospitals and Benha Children Hospital.

\section{Patients and methods \\ I. Patients}

This was a clinical preliminary examination incorporated an all out number of 100 neonates of both sex analyzed as neonatal jaundice. This examination was acted in NICU of Benha college emergency clinics and Benha kids medical clinic from May 2019 to October 2019 .

The subjects were separated into two gatherings :

1. Group I (knead gathering): included 50 neonates with hyperbilirubinemia and got rub treatment .
2. Group II (Control gathering): included 50 neonates with hyperbilirubinemia .

\section{Consideration rules}

Sound full-term (gestational age, 37-41weeks) neonates, birth weight of 2500-3600 g, APGAR score during childbirth of $8-10$, and getting phototherapy for hyperbilirubinemia

\section{Avoidance models}

Neonates with rhesus and ABO contradiction, subgaleal drain, inherent inconsistencies, diseases, a glucose-6-phosphate dehydrogenase lack, gastrointestinal hindrance, and biliary atresia.

\section{Techniques}

All cases exposed to the accompanying

1. Cautious history taking: a. Newborn child sexual orientation. b. Gestational age. c. Birth weight. d. Apgar score during childbirth. e. Obstetric information .

2. Clinical Examination included: a. Fundamental information: internal heat level, respiratory rate, pulse. b. Appearance: jaundice or paleness. c. Anthropometric estimations. d.Hepatosplenomegaly \&palpable flank masses. e. Indications of kernicturs. f. Cephalhaematoma.

3.Laboratory examination: Complete blood picture , Bilirubin level (immediate and aberrant), Blood bunches ( $\mathrm{ABO}$ and $\mathrm{Rh}$ ), Coomb's test and retic tally .

\section{Ethical contemplations}

Educated assents was acquired from every one of neonates' gatekeepers remembered for this investigation which was endorsed by the nearby moral board of Benha University and Benha kids medical clinic . 


\subsection{Statistical investigation}

The gathered information was overhauled, coded, organized and acquainted with a PC utilizing Statistical bundle for Social Science (IBM Corp. Discharged 2011. IBM SPSS Statistics for Windows, Version 20.0. Armonk, NY: IBM Corp.). Information were introduced and appropriate examination was finished by the kind of information acquired for every parameter.

Shapiro test was done to test the ordinariness of information conveyance.

\section{- Descriptive measurements}

Mean, Standard deviation ( \pm SE or SE) for numerical information. Recurrence and level of nonnumerical information.

\section{- Analytical measurements}

Understudy $\mathrm{T}$ Test was utilized to survey the measurable noteworthiness of the distinction between two investigation bunch implies. Chi-Square test was utilized to inspect the connection between two subjective factors. Fisher's accurate test: was utilized to analyze the connection between two subjective factors when the normal include is under 5 in over $20 \%$ of cells. Connection investigation: To survey the quality of relationship between two quantitative factors. The connection coefficient characterizes the quality and bearing of the straight connection between two factors. Relapse examination: Linear relapse investigation was utilized for forecast of hazard factors.

- N.B: $p$ is huge if $<0.05$ at certainty interim $95 \%$.

\section{Results}

Table (1) Basal data in all studied neonates.
This Table shows that Healthy full-term neonates were included in the current study, birth weight of 2500 $3600 \mathrm{~g}$ with mean of $3058.6 \mathrm{~g}$, APGAR score at birth of 8-10, with mean o 9.2 Table (1).

This Table shows that Mean hemoglobin concentration was $15.7 \mathrm{~g} / \mathrm{dL}$, mean reticulocytic count was $1.1 \%$. Mean stool frequency was 5.3 times, mean TSB was $18.9 \mathrm{mg} / \mathrm{dLTable} \mathrm{(2).}$

No significant differences were found in basal laboratory data and defecation frequency between all studied groups Table (3).

Defecation frequency increased by time in control and massage groups. No significant differences were found in defecation frequency between massage and control groups by the first and second days. While, by the third day, defecation frequency was significantly higher in massage group when compared t control group Table (4).

TSB level decreased by time in control and massage groups . No significant differences were found in TSB level between massage and control groups by the first and second days. While, by the third day, TSB level was significantly lower in massage group when compared to control group Table (5).

Linear regression analysis was conducted for prediction of higher TSB by the third day, using gender, delivery mode, family history, birth weight, APGAR score, hemoglobin, RC, basal TSB, phototherapy duration and massage therapy as covariates. phototherapy duration and massage therapy were considered as independent predictors of lower TSB by the third day in neonates with hyperbilirubinemia Table (6).

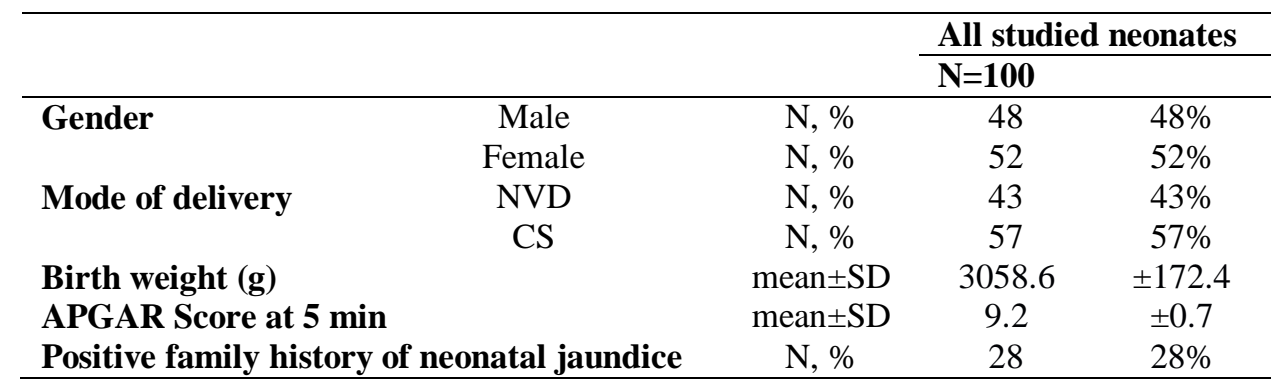

$\mathrm{SD}$, standard deviation.

Table (2) Basal laboratory data and defecation frequency in all studied neonates.

\begin{tabular}{llcc}
\hline & & \multicolumn{2}{c}{ All studied neonates } \\
\cline { 3 - 4 } & & \multicolumn{2}{c}{$\mathbf{N = 1 0 0}$} \\
\hline Hemoglobin (g/dL) & mean \pm SD & 15.7 & \pm 1.1 \\
Reticulocytic count $(\%)$ & mean \pm SD & 1.1 & \pm 0.2 \\
defecatin frequency & mean \pm SD & 5.3 & \pm 1.6 \\
TSB (mg/dL) & mean \pm SD & 18.9 & \pm 1.1 \\
\hline
\end{tabular}


Table (3) Comparison of basal laboratory data and defecation frequency between all studied groups.

\begin{tabular}{lcccccc}
\hline & & \multicolumn{2}{c}{ Control group } & \multicolumn{2}{c}{ Massage group } & p \\
\cline { 3 - 6 } & & \multicolumn{2}{c}{$\mathbf{N = 5 0}$} & \multicolumn{2}{c}{$\mathbf{N = 5 0}$} & \\
\hline Hemoglobin (g/dL) & mean \pm SD & 16.3 & \pm 1.0 & 15.1 & \pm 0.7 & 0.128 \\
Reticulocytic count (\%) & mean \pm SD & 1.1 & \pm 0.2 & 1.1 & \pm 0.2 & 0.514 \\
Defecation frequency & mean \pm SD & 4.7 & \pm 0.8 & 6.5 & \pm 1.1 & 0.111 \\
TSB (mg/dL) & mean \pm SD & 18.6 & \pm 0.8 & 19.1 & \pm 1.3 & 0.137 \\
\hline
\end{tabular}

$\mathrm{SD}$, standard deviation.

Table (4) Comparison of daily defecation in massage and control groups.

\begin{tabular}{|c|c|c|c|c|c|c|}
\hline \multirow{2}{*}{\multicolumn{2}{|c|}{ Defecation frequency }} & \multirow{2}{*}{\multicolumn{2}{|c|}{$\begin{array}{c}\text { Control group } \\
\mathbf{N}=\mathbf{5 0} \\
\end{array}$}} & \multirow{2}{*}{\multicolumn{2}{|c|}{$\begin{array}{c}\text { Massage group } \\
\mathbf{N}=\mathbf{5 0}\end{array}$}} & \multirow[t]{2}{*}{$\mathbf{p}$} \\
\hline & & & & & & \\
\hline at 1st day & mean \pm SD & 4.7 & 0.8 & 6.5 & 1.1 & 0.111 \\
\hline at $2^{\text {nd }}$ day & mean $\pm \mathrm{SD}$ & 5.5 & 0.9 & 6.1 & 1.2 & 0.085 \\
\hline at $3^{\text {rd }}$ day & mean \pm SD & 5.7 & 1.0 & 7 & 1.1 & $<0.001$ \\
\hline
\end{tabular}

$\mathrm{SD}$, standard deviation.

Table (5) Comparison of daily TSB in massage and control groups.

\begin{tabular}{|c|c|c|c|c|c|c|}
\hline \multicolumn{2}{|c|}{ TSB (mg/dL) } & \multicolumn{2}{|c|}{$\begin{array}{c}\text { Control group } \\
\mathrm{N}=50\end{array}$} & \multicolumn{2}{|c|}{$\begin{array}{c}\text { Massage group } \\
\mathbf{N}=50\end{array}$} & $\mathbf{p}$ \\
\hline at 1st day & mean \pm SD & 18.6 & 0.8 & 19.1 & 1.3 & 0.137 \\
\hline at $2^{\text {nd }}$ day & mean $\pm \mathrm{SD}$ & 16.1 & 0.8 & 14.7 & 1.1 & 0.071 \\
\hline at $3^{\text {rd }}$ day & mean $\pm \mathrm{SD}$ & 13.5 & 0.7 & 10.6 & 0.8 & $<0.001$ \\
\hline
\end{tabular}

$\mathrm{SD}$, standard deviation.

Table (6) Regression analysis for prediction of higher TSB by the third day.

\begin{tabular}{lcccc}
\hline & \multicolumn{2}{c}{ Univariable } & \multicolumn{2}{c}{ Multivariable } \\
\cline { 2 - 5 } & $\boldsymbol{\beta}$ & $\mathbf{P}$ & $\boldsymbol{\beta}$ & $\mathbf{P}$ \\
\hline Gender & -0.029 & 0.930 & & \\
Delivery mode & 0.212 & 0.520 & & \\
Family history & 0.440 & 0.224 & & \\
Birth weight & 0.011 & 0.989 & & \\
HemAR score & -0.189 & 0.411 & & \\
Reticulocytic count & 0.741 & 0.372 & & \\
Basal TSB & 0.113 & 0.883 & & \\
Phototherapy duration & 0.092 & 0.534 & & \\
Massage therapy & -0.142 & $<0.001$ & -0.117 & $<0.001$ \\
\hline
\end{tabular}

B, regression coeffecient.

\section{Discussion}

Our examination demonstrated that body weight was not altogether unique between the back rub and control gatherings. This outcome is predictable with [8] study, in which neglected to recognize noteworthy contrasts in weight gain between newborn children who got knead treatment and control bunch babies following a month of treatment.

Lin $\mathrm{CH}$ study, the absence of a noteworthy increment in body weight increase after back rub may have been a direct result of the youthful age of the members (normal age: $4.9 \pm 2.5$ days in the back rub gathering; $4.5 \pm 1.7$ days in the benchmark group) . In our investigation, it is conceivable that the reason is because of the length of back rub treatment was too short to even consider stimulating the emission of insulin and IGF-1.

Notwithstanding, the ongoing writing has demonstrated that rub treatment can expand weight gain in preterm newborn children who get moderate-pressure knead for 10 min three times each day more than 5 days [10] . 
While [11] announced that both body weight and tallness essentially expanded in kneaded babies contrasted and control newborn children following 2 and 14 weeks of back rub treatment.

T.Field indicated that preterm neonates who got knead treatment for a 5-day time span had more prominent increments in weight gain, serum insulin levels, and insulin-like development factor-1 (IGF-1), the creators estimated that weight increase following back rub may have been because of increments in insulin/IGF1 levels or vagal movement, which, thusly, could have diminished pressure and gastric motility, prompting progressively effective food ingestion .

As per [13] study, knead treatment has prompted weight gain in newborn children, increment in bone thickness and decline level of bilirubin.

The crap recurrence in the back rub gathering of this investigation was altogether higher than that in the benchmark group on the third day of back rub treatment, which is tantamount with the consequences of past examinations [9] .

In the investigation by [14] the poo recurrence of newborn children who got rub treatment was essentially higher than that in the benchmark group by the fourth day of treatment. Additionally, in the investigation by [7] the mean poop recurrence of the back rub bunch was altogether higher than that of the benchmark group on the initial 2 days of treatment. In any case, neither of these investigation populace included neonates accepting phototherapy for jaundice.

Past research has shown that most neonates first pass dung inside $24 \mathrm{~h}$ of birth, in spite of the fact that rub treatment can invigorate the section of meconium. This may clarify the altogether higher poop recurrence that we saw in the back rub bunch by the third day of treatment. Back rub treatment can expand solid discharges and the discharge of meconium, and an expanded recurrence of defecations may be required to reduce the enterohepatic flow of bilirubin in a neonate, in this way prompting expanded bilirubin discharge [15] .

In our examination, the bilirubin level of the back rub bunch neonates was altogether lower than that of the benchmark group on the third day of back rub treatment. This outcome is steady with the investigation by [7] who revealed that in fullterm neonates with jaundice, bilirubin levels were altogether diminished in the back rub bunch contrasted and the benchmark group on the fourth day of treatment. Also, [16] demonstrated that the mean bilirubin level of newborn children with jaundice in the back rub bunch altogether diminished on the fourth day contrasted and the benchmark group.

Likewise in this examination, the poo recurrence was altogether higher in the back rub bunch than in the benchmark group on the third day of treatment. Expanded crap may in this manner clarify the huge decrease in bilirubin levels saw in the back rub gathering.

Besides, knead treatment likewise animates the vagus nerve, which will build the recurrence of defecations and lessen the enterohepatic course of bilirubin, subsequently expanding bilirubin discharge [14]. Moreover, in subcutaneous tissue, physiological back rub treatment can expand the progression of blood, lymph, and tissue liquids, which builds the assortment and discharge of waste items, for example, bilirubin [7].

Back rub treatment could prompt prior decreases in bilirubin levels that may permit shorter medications with phototherapy, bringing about prior release. The most probable system fundamental the decrease in neonatal jaundice in the gathering accepting back rub treatment is the incitement of intestinal development. This, thus, will build crap recurrence and permit the neonate to pass more noteworthy measures of meconium, which contains bilirubin [7] .This is steady with the discoveries of Gourley et al., who noticed that stool creation and serum bilirubin levels were contrarily corresponded in solid term newborn children during the primary seven day stretch of life [17] .

In R.Lori Kenari [18] study, there was a noteworthy contrast between two gatherings of control and back rub regarding span of hospitalization and phototherapy just as bilirubin level. What's more, the span of hospitalization declined from 95 to 81 hours and the term of phototherapy decreased from 84 to 74 hours in the back rub field gathering. Additionally, as indicated by the consequences of the main day, there was no distinction in crap between the gatherings, however on the second and the third day in the back rub bunch there was an expansion in poop and there was a noteworthy contrast in the benchmark group.

The consequences of last examination are perfect with those of $[7,19,20]$ who expressed that newborn child back rub could expand the quantity of crap and in this way diminish the bilirubin level in neonates under phototherapy. Be that as it may, are opposing with those of [21] who found no huge contrast among control and back rub bunches as far as transcutaneous bilirubin level and span of phototherapy. Be that as it may, an expansion in crap was seen in babies in the mediation gathering, which could diminish bilirubin levels in newborn children [21]. The disparity between the discoveries might be because of less incessant day by day kneads (twice), particularly in untimely babies, as indicated by [6] rub.

In the ongoing investigation direct relapse examination was led for expectation of higher TSB by the third day, utilizing sexual orientation, conveyance mode, family history,birth weight, APGAR score, hemoglobin, RC, basal TSB, phototherapy length and back rub treatment as covariates. We found that phototherapy term and back rub treatment were considered as autonomous indicators of lower TSB by the third day in neonates with hyperbilirubinemia.

\section{Conclusion}

This examination shows that by the third day of intercession, the poop recurrence of neonates getting phototherapy for jaundice was essentially higher in those 
accepting back rub treatment contrasted and the benchmark group not accepting back rub treatment.

Moreover, complete serum levels of bilirubin were fundamentally lower in the examination bunch on the third day. Be that as it may, the advantages of back rub treatment stay dubious for neonatal jaundice, and in spite of the fact that this investigation adds to the proof in support of its, further research is expected to explain the genuine impacts of such helper medicines on the results of neonatal jaundice.

\section{References}

[1] B.O.Olusanya, M.Kaplan and T.W.Hansen, Neonatal hyperbilirubinaemia: a global perspective. The Lancet Child \& Adolescent Health, Vol.2(8), PP.610-620, 2018.

[2] BL.Burke, JM.Robbins, TM.Bird et al, Trends in hospitalization for neonatal jaundice and kernicterus in the United States, 19882005. Pediatrics;Vol.123, PP.524-32, 2009.

[3] I.Topal, C.Mertoglu, I.Surucu Kara et al , Thiol-disulfide homeostasis, serum ferroxidase activity, and serum ischemia modified albumin levels in neonatal jaundice. Fetal Pediatr Pathol, Vol.38, PP. 138-45, 2009.

[4] National Collaborating Centre for, Women's and Children's, Health. Neonatal Jaundice ( 2016 ). RCOG Press Royal College of Obstetricians and Gynaecologists (Update information Oct 2016. Available at: https://www.nice.org.uk/guidance/cg98/eviden ce/full-guideline-245411821.

[5] RM.Kliegman, BM.Stanton BM, JS.Geme et al. , Nelson textbook of pediatrics. E-Book: $21 \mathrm{st}$ ed. Elsevier Health Sciences 2019. Available at:

https://www.elsevier.com/books/nelson-

textbook-of-pediatrics-2-volume-

set/kliegman/978-0-323-52950-1, 2019.

[6] M.Kianmehr, A.Moslem, K.Basiri et al., The effect of massage on serum bilirubin levels in term neonates with hyperbilirubinemia undergoing phototherapy. Nautilus; Vol.128, PP. 36-41, 2014.

[7] J.Chen, M.Sadakata, M.Ishida and M.Sayama, Baby massage ameliorates neonatal jaundice in full -term new born infants. Tohoku J.Exp.Med, Vol.223, PP. 97-102, 2011.

[8] HK.Lee, The effects of infant massage on weight, height, and mother-infant interaction. Taehan Kanho Hakhoe Chi, Vol.36, PP.13319, 2006.

[9] CH.Lin, HC.Yang, CS.Cheng, et al., Effects of infant massage on jaundiced neonates undergoing phototherapy. Ital J Pediatr; Vol.41, p.94, 2015.

[10] MA.Diego , T.Field, M.Hernandez-Reif, Preterm infant weight gain is increased by massage therapy and exercise via different underlying mechanisms. Early Hum Dev, Vol.90, PP.137-40, 2014.

[11] HB.Y1lmaz, Z.Conk, The effect of massage by mothers on growth in healthy full term infants. IJHS, PP.6:969-77, 2009.

[12] T.Field, M.Diego, M.Hernandez-Reif, et al, Insulin and insulin-like growth factor-1 increased in preterm neonates following massage therapy. J Dev Behav Pediatr; Vol.29, PP.463-6, 2008.

[13] P.Church, A.Cavanagh and V.Shah, Academic Challenges for the Preterm Infant: parent and educator perspectives, Paediatrics \& Child Health, Vol.21(5), p.E84, 2016.

[14] A.Seyyedrasooli, L.Valizadeh, MB . Hosseini et al, Effect of vimala massage on physiological jaundice in infants: a randomized controlled trial. J Caring Sci , Vol.3, PP.165-73, 2016.

[15] BA.Semmekrot, MC de Vries, GP Gerrits et al., Optimal breastfeeding to prevent hyperbilirubinaemia in healthy, term newborn. Ned Tijdschr Geneeskd, Vol.148, PP.201619, 2004.

[16] MB.Moghadam, KB.Moghadam, M.Kianmehr et al., Effects of massage on weight gain and jaundice in term neonates with hyperbilirubinemia. J Isfahan Med. , Vol.30, PP.1-8, 2012.

[17] GR.Courley, B.Kreamer, R.Arend, The effect of diet on feces and jaundice during the first 3 weeks of life. Gastroenterology, Vol.103, PP.660-67, 1992.

[18] R.Lori Kenari, P.Aziznejadroshan, M.Haghshenas Mojavaeri et al., Comparing the effect of kangaroo mother care and field massage on serum bilirubin level of term neonates with hyperbilirubinemia under phototherapy in the neonatal ward. Caspian $\mathrm{J}$ Intern Med, Vol.11(1), PP.34-40, 2020.

[19] H.Dalili, S.Sheikhi, M.Shariat et al, Effects of baby massage on neonatal jaundice in healthy Iranian infants: a pilot study. Infant Behav Dev, Vol. 42, PP. 22-6, 2016.

[20] A.Jalalodini, M.Nourian, L.Goodarzvand et al , The effect of tactile-kinesthetic massage on transcutaneous bilirubin in term neonates with hyperbilirubinemia care with phototherapy. IJNR, Vol.11, PP. 13-9, 2016.

[21] S.Karbandi, H.Boskabadi, H.Esmaeily et al, Effects of massage on duration of phototherapy in premature infants admitted to a neonatal intensive care unit. $J$ Babol Univ Med Sci, Vol.18, PP.11-17, 2016. 